\title{
Early and individualized goal-directed therapy for trauma-induced coagulopathy
}

Herbert Schöchl ${ }^{1,2 *}$, Marc Maegele ${ }^{3}$, Cristina Solomon ${ }^{1}$, Klaus Görlinger $^{4}$ and Wolfgang Voelckel ${ }^{2}$

\begin{abstract}
Severe trauma-related bleeding is associated with high mortality. Standard coagulation tests provide limited information on the underlying coagulation disorder. Whole-blood viscoelastic tests such as rotational thromboelastometry or thrombelastography offer a more comprehensive insight into the coagulation process in trauma. The results are available within minutes and they provide information about the initiation of coagulation, the speed of clot formation, and the quality and stability of the clot. Viscoelastic tests have the potential to guide coagulation therapy according to the actual needs of each patient, reducing the risks of over- or under-transfusion. The concept of early, individualized and goal-directed therapy is explored in this review and the AUVA Trauma Hospital algorithm for managing trauma-induced coagulopathy is presented.
\end{abstract}

Keywords: ROTEM, TEG, trauma, goal-directed coagulation therapy

\section{Introduction}

Major brain injury and uncontrolled blood loss remain the primary causes of early trauma-related mortality [1-3]. One-quarter to one-third of trauma patients exhibit trauma-induced coagulopathy (TIC) [4,5], which is associated with increased rates of massive transfusion (MT) and multiple organ failure (MOF), prolonged intensive care unit and hospital stays, and a four-fold increase in mortality [4]. Most patients with coagulopathy also have uncontrolled bleeding, and early diagnosis of the underlying coagulation disorder is paramount for effective treatment.

One major challenge in treating severely bleeding trauma patients is to determine whether the blood loss is attributable to surgical causes or coagulopathy. If the patient is coagulopathic, it is paramount to characterize the cause of the coagulopathy and whether thrombin generation is impaired or clot quality or stability is diminished. Recent data suggest that whole-blood viscoelastic tests, such as thromboelastometry $\left(\right.$ ROTEM $^{\circledR}$, Tem International GmbH, Munich, Germany) or thrombelastography (TEG ${ }^{\circledR}$, Haemonetics Corp., Braintree, MA, USA) portray trauma induced coagulopathy (TIC)

\footnotetext{
* Correspondence: Herbert.schoechl@auva.at

'Ludwig Boltzmann Institute of Experimental and Clinical Traumatology, Vienna, Austria

Full list of author information is available at the end of the article
}

more accurately and substantially faster than standard coagulation tests [6-8]. There is increasing evidence that these coagulation monitoring devices are helpful in guiding coagulation therapy for heavily bleeding trauma patients according to their actual needs [9].

The intention of this review is to examine the concept of individualized, early, goal-directed therapy for TIC, using viscoelastic tests and targeted coagulation therapy. In addition, the AUVA Trauma Hospital algorithm for managing TIC is presented.

\section{Value of standard coagulation tests}

Fast, reliable diagnosis and characterization of TIC is important. Standard coagulation tests (e.g. prothrombin time $[\mathrm{PT}]$, international normalized ratio [INR], prothrombin time index [PTI] and activated partial thromboplastin time [aPTT]) fail to accurately describe the complex nature of TIC for several reasons [4,5]. In vivo coagulation occurs primarily on the surface of platelets and tissue factor-bearing cells [10], and red blood cells (RBCs) also play a significant role in haemostasis [11]. Standard coagulation tests are performed using plasma in the absence of blood cells (these are removed by centrifugation). Also, these tests are stopped upon formation of the first fibrin strands, when only $\sim 5 \%$ of the total thrombin has been generated [12]. Moreover, these tests do not assess the quality/the strength of the clot. 
Hyperfibrinolysis is recognized as a potential contributor to mortality in trauma [13-15], and this aspect is not assessed by standard coagulation tests [16].

Coagulation factors do not decrease homogeneously in severe bleeding. Although there may be a tendency towards excessive thrombin generation, coagulation factor levels are decreased and fibrinogen appears to reach critical levels at an early stage [17-19]. Therefore, measurement of fibrinogen concentration is strongly recommended in trauma patients $[14,19]$. However, when using artificial colloids, falsely high fibrinogen levels are recorded by some coagulation analysers that employ the Clauss method [20,21]. Artificial colloids also impair fibrin polymerization, and standard laboratory measurement does not represent fibrinogen functionality [22].

Another shortcoming of standard coagulation tests, including fibrinogen concentration measurement, is that the results are available only after a substantial time delay. Median turnaround times of 78-88 minutes have been reported [23,24].

In summary, standard coagulation tests are unable to characterize the complex nature of TIC. They are timeconsuming and offer little prognostic value regarding transfusion requirements [25].

\section{Role of thromboelastometry/thrombelastography}

Trauma care providers are increasingly aware that viscoelastic coagulation monitors such as thromboelastometry (ROTEM) and thrombelastography (TEG) are valuable alternatives to standard coagulation testing, providing a more comprehensive overview of the coagulation process $[6,8,23,26-29]$. In contrast to most standard coagulation measurements, ROTEM and TEG can be used as point-of-care methods. Viscoelastic tests are performed in whole blood as opposed to plasma, which provides a better reflection of the in vivo situation, avoids the need for centrifugation and allows initial results to be available within minutes $[23,30]$.

ROTEM and TEG tests provide dynamic information on the speed of coagulation initiation, kinetics of clot growth, clot strength, and breakdown of the clot $[16,31]$. The ROTEM device uses a plastic pin immersed vertically into a cup containing the blood sample; the pin is rotated slowly, backwards and forwards, through an angle of $4.75^{\circ}$. The device has four channels, allowing four tests to be performed simultaneously. Two basic ROTEM tests that use intrinsic activation (INTEM) and extrinsic activation (EXTEM) provide information on the general coagulation status (impaired, normal, and hypercoagulable). Figure 1 shows examples of EXTEM plots with normal and impaired coagulation. A set of standard reagents can additionally be used to characterize coagulopathy. For example, the FIBTEM test, which comprises the EXTEM assay with added cytochalasin D to inhibit platelets, provides information on the fibrin component of the clot.

The TEG device uses a stationary torsion wire and the cup is rotated. TEG is a two channel system that uses either kaolin as an activator or a combination of kaolin and tissue factor ('rapid TEG' or 'r-TEG' assay). The

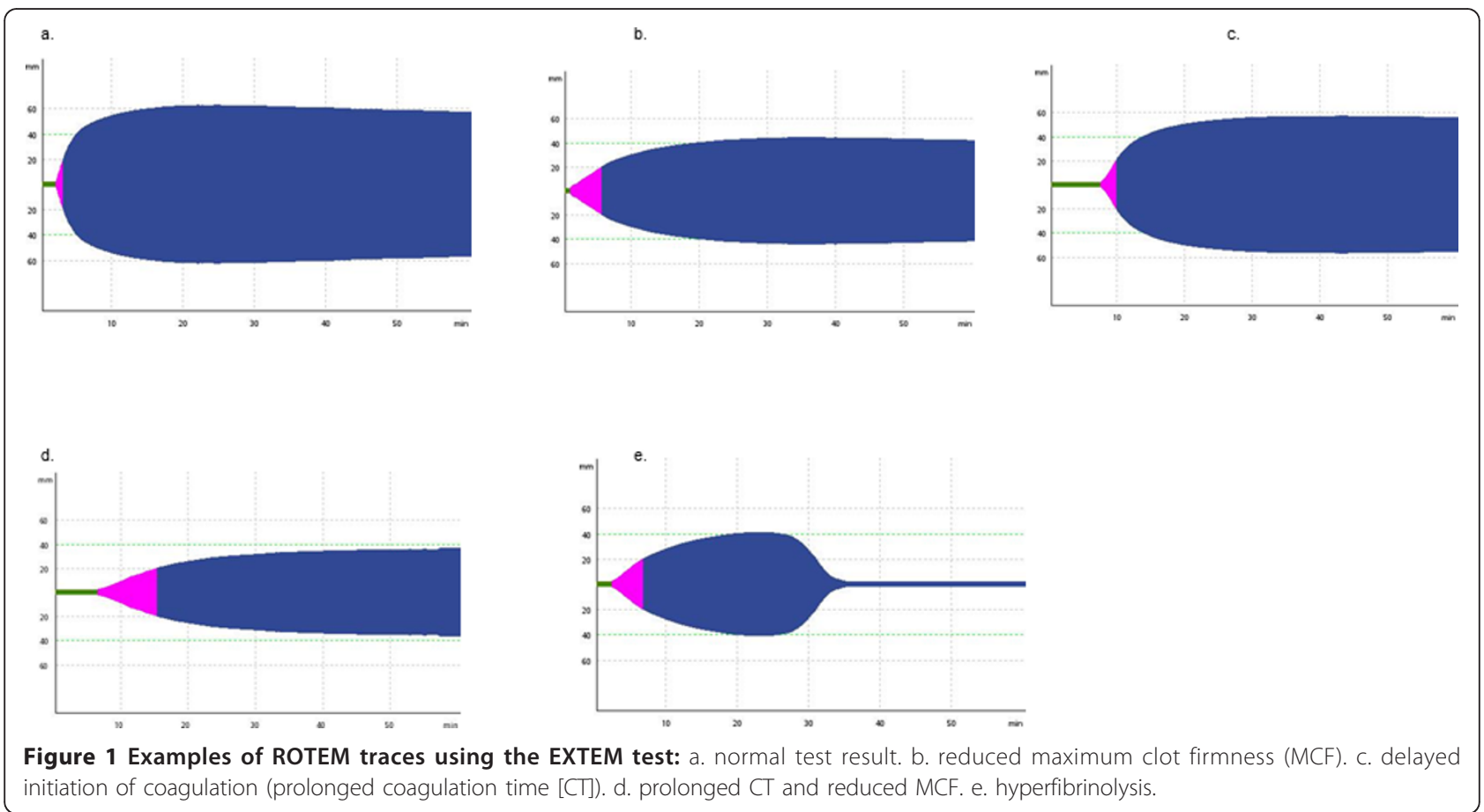


functional fibrinogen test is equivalent to the ROTEM FIBTEM test. These methods and devices are described in detail elsewhere [16,31].

\section{Assessment of platelet function}

Platelet count provides quantitative information on platelet numbers, but it provides no information on platelet function. Prior treatment with platelet inhibitors such as aspirin or thienopyridines is commonly encountered among emergency room patients and, although platelet function may potentially influence patient outcomes [32], platelet inhibitor therapy cannot be assessed adequately by standard viscoelastic analyses [33]. POC monitoring devices allowing rapid assessment of platelet function (e. g. Multiplate ${ }^{\circledR} ;$ Roche Diagnostics, Munich, Germany) have been developed recently [34]. Whole blood is added to test cells which incorporate two independent sensor units. Platelet aggregation takes place on the sensor units following addition of a platelet activator. Different platelet activators are used such as adenosine diphosphate (ADPtest), arachidonic acid (ASPItest), and thrombin receptor-activating peptide-6 (TRAP-6; TRAPtest). The platelets' ability to adhere to the metal sensors and build aggregates is measured by the electrical resistance change between two sensor wires. The impedance change between each pair of wires is recorded as an aggregation curve and expressed in "aggregation units" (U). In the AUVA trauma hospital, Mulitplate was used as a diagnostic tool for assessing platelet function in all patients admitted to the ER between 2009 and 2011 [32]. In light of our data published in 2011, [32] we now use Multiplate only in patients who are unconscious (meaning that anamnesis is impossible) or known to be taking platelet inhibitor medication.

\section{Rationale for massive transfusion protocols}

It has been shown that the majority of massively transfused patients who exsanguinated within the first 24 hours after hospital admission received insufficient amounts of fresh frozen plasma (FFP) and platelet concentrate (PC) [35]. Inadequate replacement of coagulation factors during the initial care was identified as the main cause of prolonged INR upon admission to the intensive care unit (ICU) [36]. Recent data indicate that early and aggressive transfusion of FFP and PC is associated with improved survival rates among major trauma patients [37-42]. To increase the effectiveness of coagulation therapy, massive transfusion protocols (MTPs) have been implemented. Predefined sets of RBC concentrate, FFP and PC are issued by the blood bank after the activation of such MTPs [43,44]. However, MTPs vary in format between trauma centres, with different ratios of FFP to RBCs and PC [45]. MT prediction scores have been developed for early identification of at-risk patients, with the aim of initiating MTPs as early as possible thereby minimizing treatment delays. These scores are based on anatomic findings and/or rapidly available laboratory data such as PT and base deficit [46-49].

\section{What is the optimal ratio of FFP:RBC?}

It has long been assumed that high-volume plasma replacement therapy may potentially avoid or correct coagulopathy in severely bleeding patients. A computer model by Hirshberg et al. has indicated that late transfusion of plasma may be insufficient for preventing or correcting coagulopathy [50]. Moreover, the optimum FFP: RBC replacement ratio was calculated in the same study to be approximately 2:3 [50]. Similarly, data from a military centre show that the optimal FFP:RBC ratio for minimizing mortality among trauma patients receiving MT is close to 1:1.4 [37]. A retrospective analysis of civilian trauma patients reported that a high FFP:RBC ratio (> 1:1) significantly lowers intraoperative, 24-hour and 30-day mortality [42]. An abundance of studies support early and aggressive coagulation management with FFP [51]. However, the optimal ratio of FFP:RBC is still under discussion $[7,52,53]$.

For example, Kashuk et al. suggest that the optimal ratio of FFP:RBC appears to be in the range of 1:2 to $1: 3$ [7], with no improvement in survival rate among patients receiving higher ratios. More recently, Davenport et al. found no improvement in coagulation status when FFP:RBC were transfused in a ratio of $1: 1 \mathrm{com}-$ pared with 1:2 or 3:4 [52]. Simmons et al. reported data from the Iraq War in which a change of clinical practice guidelines toward higher FFP:RBC ratios resulted in significantly higher FFP transfusion but no improvement in survival [54]. Similarly, implementation of an MTP targeting an FFP:RBC ratio of 1:1 in a Scandinavian trauma centre significantly increased transfusion of FFP without improving mortality [55].

\section{Timing of haemostatic intervention is crucial}

There is no doubt that coagulation therapy should be started as early as possible. Riskin et al. reported a significant reduction in mortality from $45 \%$ to $19 \%$ after implementation of an MTP despite unchanged FFP:RBC ratios. The most likely reason for the improvement was a significant reduction in mean time to administration of FFP, from 254 to 169 minutes [56]. Early haemostatic therapy appears to prevent the development of coagulopathy in some patients, eliminating the need for MT; plasma transfusion seems to be most effective during the first 23 hours of care for massively bleeding patients [57].

\section{FFP: safety and the need for selective use}

High-volume FFP transfusion is associated with considerable side effects [55,58-61]. Chaiwat et al. reported a 
dose-dependent relationship between FFP transfusion and acute respiratory distress syndrome (ARDS) in trauma patients [58]. In another study, FFP transfusion was independently associated with increased risk of MOF and ARDS in patients who survived beyond 48 hours [62].

There is little evidence that patients receiving $<10$ units $(\mathrm{U})$ of RBCs benefit from FFP transfusion. Inaba et al. showed that in non-MT trauma patients $(<10 \mathrm{U}$ $\mathrm{RBC} / 24$ hours), plasma administration increased complications (e.g. ARDS, pneumonia, sepsis and MOF), without improving survival [59]. Other data show a greater increase in side effects with FFP among patients receiving < 6 U RBCs within the first 6 hours [60]. Recently, Sambasivan et al. analysed outcome data form 1,788 non-MT patients (< $10 \mathrm{U} \mathrm{RBC} / 24$ hours) who received FFP and PC. A high ratio of FFP:RBC and PC:RBC was associated with fewer ventilator-free and fewer ICU-free days [61]. Therefore, early identification of patients who are prone to MT seems important.

In summary, FFP transfusion is associated with serious side effects, and transfusion triggers should be chosen carefully. In particular, patients receiving $<10 \mathrm{U}$ RBCs do not appear to benefit from FFP transfusion.

\section{Concept of early and individualized goal-directed coagulation therapy}

In contrast to a fixed ratio of FFP:PC:RBC, goal-directed coagulation therapy aims to adapt treatment to the actual needs of the individual patient, based on viscoelastic test results (Figure 2) [6,8]. The short turnaround times of ROTEM and TEG assays allow rapid diagnostic testing and individualized drug therapy to be based on test results, with a feedback loop to monitor and optimize treatment effectiveness and to minimize sideeffects. This "theragnostic" concept offers several potential advantages, and these are discussed below.

Rapid assessment of coagulation status and prediction of the need for massive transfusion

In severe trauma patients, it is crucial to receive rapid information on the patient's current coagulation status. The first ROTEM or TEG test results are available within minutes [30]. Low maximum clot firmness (MCF) in EXTEM, INTEM and FIBTEM or maximum amplitude (MA, the equivalent TEG parameter) has been identified as an important determinant of RBC transfusion [23,30,63-67]. In one study, MA but not standard coagulation tests (INR, PT, aPTT) was predictive for blood product transfusions [66]. Leemann et al. showed that low INTEM MCF and low haemoglobin levels were independent risk factors for MT [63]. TEG clot strength $(G)$ on admission to the ER has been reported to provide consistent prediction of MT in trauma patients [65]. Davenport et al. observed that
ROTEM clotting times in trauma patients show only a trend toward prolongation in coagulopathic patients (116 vs. 66 seconds; $\mathrm{p}=0.0068$ ). However, EXTEM clot amplitude $<35 \mathrm{~mm}$ at 5 minutes was identified as a predictor of MT with a detection rate of $71 \%$ [23]. A retrospective study of major trauma patients (ISS $>16$ ) showed that a low FIBTEM amplitude $(<4 \mathrm{~mm})$ and/or a low EXTEM amplitude $(<35 \mathrm{~mm})$ at 10 minutes (CA10) reliably predicts MT [30].

\section{AUVA TRAUMA HOSPITAL TREATMENT ALGORITHM FOR TIC - DIAGNOSIS}

To provide rapid information on the coagulation status of major trauma patients: run ROTEM tests (EXTEM, INTEM, FIBTEM and APTEM) to assess clotting times and/or clot quality on admission to the ER. For patients who are unconscious or known to be taking platelet inhibitor medication, Multiplate tests (adenosine diphosphate [ADP] test, arachidonic acid [ASPI] test, and thrombin receptor activating peptide- 6 [TRAP] test) are also performed, to assess platelet function.

\section{Improving and maintaining clot quality in TIC}

Based on the evidence available, it appears reasonable to focus goal-directed coagulation therapy on the maintenance or restoration of clot strength. Clot strength is determined by interactions between the fibrin network, activated platelets and activated factor XIII.

\section{Fibrinogen supplementation}

Fibrinogen seems to reach critically low levels very early after trauma $[9,13,23,30]$. Current European guidelines recommend a plasma fibrinogen concentration in trauma patients of no less than 1.5-2.0 g/L [29]. However, there is limited evidence that fibrinogen administration improves outcomes in trauma patients. A retrospective military study reported increased survival among patients receiving a high fibrinogen:RBC ratio (0.48 g fibrinogen per unit of RBCs), compared with those receiving a lower ratio $(0.1 \mathrm{~g}$ fibrinogen per unit of RBC) [68].

FFP is one potential source of fibrinogen, but it is collected from healthy volunteers who may occasionally have low fibrinogen levels. Fibrinogen concentrations of $\sim 2 \mathrm{~g} / \mathrm{L}$ have been found in both FFP and solvent-detergent (SD) plasma [69]. Chowdhury et al. compared changes in coagulation factor levels after FFP transfusion of $12 \mathrm{~mL} / \mathrm{kg}$ bodyweight or $35 \mathrm{~mL} / \mathrm{kg}$ bodyweight, and observed a substantial increase in fibrinogen solely in the high-FFP volume group [70]. Prior to infusion, FFP must be thawed and this is a time-consuming process. Pre-thawing of FFP may avoid this delay, but storage time is limited. Lyophilized plasma, which is 


\section{Algorithm for treating bleeding in patients with trauma-induced coagulopathy}

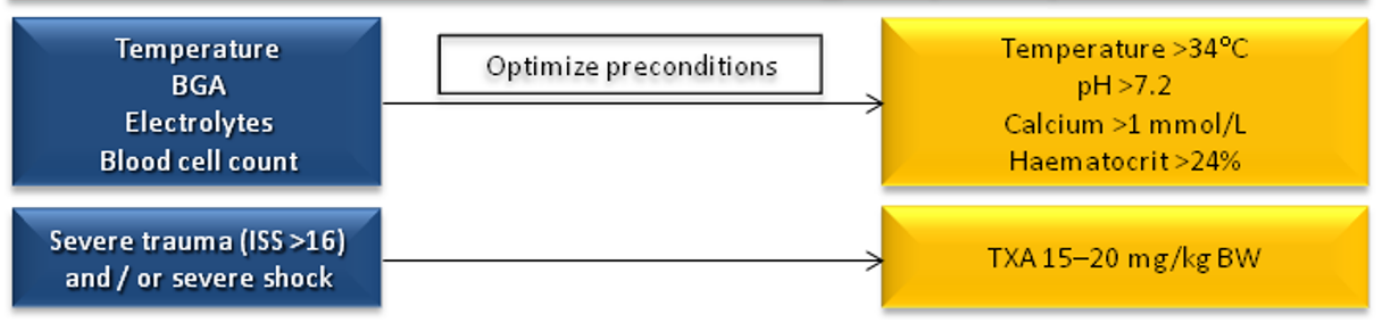

\section{Run ROTEM (EXTEM, INTEM, FIBTEM, APTEM)*}
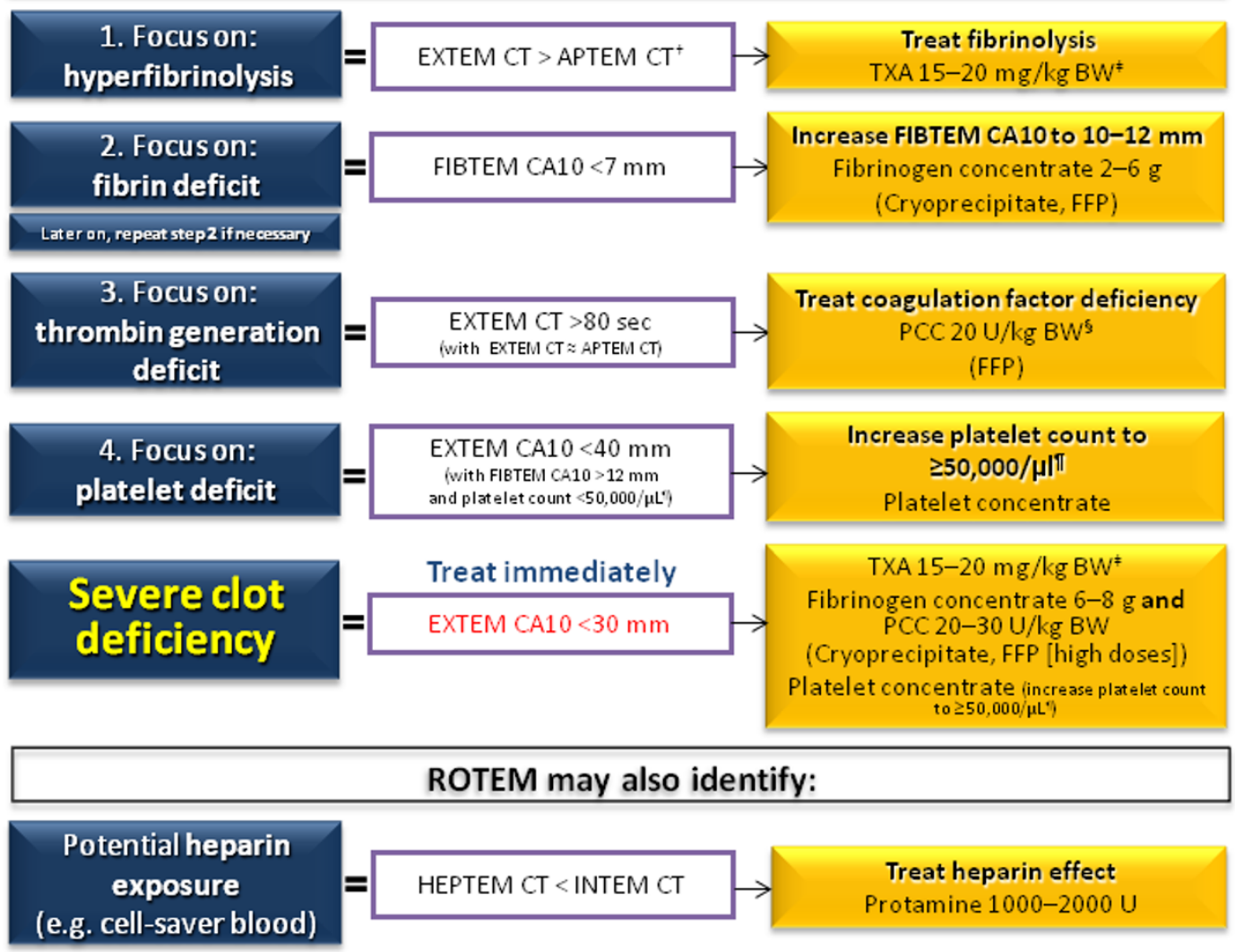

Treat heparin effect Protamine $1000-2000 \mathrm{U}$
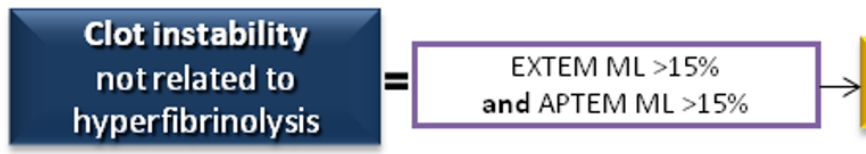

\section{Consider}

Factor XIII $1250 \mathrm{U}$

Figure 2 ROTEM-guided treatment algorithm: managing trauma-induced coagulopathy and diffuse microvascular bleeding (AUVA Trauma Hospital, Salzburg, Austria). The algorithm represents standard operating procedure for ROTEM-guided haemostatic therapy upon admission of trauma patients to the emergency room. In parentheses: haemostatic agents suggested for use in clinics where coagulation factor concentrates are not available. * For patients who are unconscious or known to be taking platelet inhibitor medication, Multiplate tests (adenosine diphosphate [ADP] test, arachidonic acid [ASPI] test, and thrombin receptor activating peptide-6 [TRAP] test) are also performed. ${ }^{\S}$ If decreased ATIII is suspected or known, consider co-administration of ATIII. ${ }^{\dagger}$ Any major improvement in APTEM parameters compared to corresponding EXTEM parameters may be interpreted as a sign of hyperfibrinolysis. ${ }^{*}$ Only for patients not receiving TXA at an earlier stage of the algorithm. Traumatic brain injury: platelet count 80,000-100,000/ $\mu$ l. Normal values: EXTEM/APTEM coagulation time (CT): 38-79 seconds; EXTEM/APTEM clot amplitude at 10 minutes (CA10): $43-65$ mm; EXTEM/APTEM maximum lysis (ML) < 15\%; FIBTEM CA10: 7-23 mm; INTEM CT: 100-240 seconds. CA10, clot amplitude at 10 minutes; BGA, blood gas analysis; BW, body weight; Ca, calcium; CT, clotting time; FFP, fresh frozen plasma; ISS, injury severity score; MCF, maximum clot firmness; ML, maximum lysis; PCC, prothrombin complex concentrate; TXA, tranexamic acid. 
immediately available in the ER, represents a possible future solution to these problems [71].

Cryoprecipitate, another source of fibrinogen, is still available in the US and the UK, but it has been withdrawn from some European countries in response to significant safety concerns [72]. The fibrinogen content of a unit of cryoprecipitate can vary widely, from 120 to $796 \mathrm{mg}$ [73]. In patients not receiving plasma components within the preceding 2 hours, cryoprecipitate has been reported to produce a mean increase in fibrinogen concentration of $\sim 0.06 \mathrm{~g} / \mathrm{U}$ [74]. If using cryoprecipitate to increase plasma fibrinogen concentration, European Guidelines recommend transfusion of $15-20 \mathrm{U}$ in a 70$\mathrm{kg}$ adult [29]. Only limited data show improved survival following transfusion of cryoprecipitate in trauma patients [62].

Fibrinogen concentrate is licensed in some European countries for congenital and acquired bleeding. It can be reconstituted easily and quickly using sterile water or saline [75], allowing rapid and controlled dosing. Approximately $3 \mathrm{~g}$ of fibrinogen concentrate is required to raise the plasma concentration by $1 \mathrm{~g} / \mathrm{L}$ in a $70-\mathrm{kg}$ patient [76]. Fibrinogen concentrate can be administered without thawing or cross-matching, significantly reducing time to infusion [8]. In emergency cases, administration of $6 \mathrm{~g}$ in 1-2 minutes has been reported [76]. Post-treatment improvements in clot formation and clot strength can be monitored using viscoelastic tests $[8,76]$. The safety profile of fibrinogen concentrate appears to be favourable with a low risk of thromboembolic events [77-79], although the available data cannot be considered as definitive in this regard.

\section{AUVA TRAUMA HOSPITAL TREATMENT ALGORITHM FOR TIC}

FIBTEM CA10 $<7 \mathrm{~mm}$ suggests insufficient fibrin clot formation. Fibrinogen concentrate should be administered until a FIBTEM CA10 of $10-12 \mathrm{~mm}$ is reached.

\section{Platelet transfusion}

Platelets are important determinants of clot quality and serve as a matrix for coagulation factors [11]. Upon ER admission, platelet count $<150,000 / \mu \mathrm{L}$ has been reported in only $4 \%$ of trauma patients with an injury severity score (ISS) of 5 and in $18 \%$ of patients with ISS $>45$ [80].

In bleeding trauma patients, it is recommended to maintain platelet count $>50,000 / \mu \mathrm{L}$ and in patients with substantial brain injury, a platelet count $>100,000 / \mu \mathrm{L}$ is suggested as optimal [29]. However, the value of platelet transfusion in a fixed, predefined ratio for the management of TIC is currently unclear. The reported improvements in survival associated with platelet transfusion are subject to survival and selection biases similar to those seen with FFP and the efficacy and safety of platelet transfusion in a predetermined ratio has not been established. Holcomb et al. reported improved early and late survival and decreased rates of haemorrhagic deaths in patients receiving a high ratio of PC: RBC. As a potential side effect of increased platelet transfusion, MOF increased as the PC:RBC ratio increased [81]. The MTP published by Dirks et al. resulted in a significant increase in PC transfusion without any improvement in the survival rate [55]. Similar results were reported by Simmons et al., who observed that the introduction of new clinical practice guidelines forcing early platelet transfusion resulted in no survival benefit [54]. Thus, platelet transfusion in a fixed predefined ratio carries the potential for wasting valuable resources and the risk of complications (e.g. transfusionrelated acute lung injury, pathogen transmission).

\section{AUVA TRAUMA HOSPITAL TREATMENT ALGORITHM FOR TIC \\ EXTEM CA10 < $40 \mathrm{~mm}$ and FIBTEM CA10 > 12 $\mathrm{mm}$ and platelet count $<50,000 / \mu \mathrm{L}$ suggests suffi- cient fibrin clot formation, but insufficient platelets to produce adequate clot strength. Platelet concen- trate transfusion is indicated.}

\section{Improving initiation of the coagulation process}

Thrombin generation is not substantially affected in the early stages of TIC [82]. Brohi et al. reported that generation of prothrombin fragment ${ }_{1-2}$ increased with increasing ISS [83]. Thrombin generation in patients with possible TIC (PT > 18 seconds or INR $>1.5$ ) has been reported as threefold higher than in controls $(\mathrm{p}=$ 0.01) [17]. The concept of of early, high-dose FFP transfusion with the aim of increasing thrombin generation must be debated in the light of adequate or even increased thrombin generation in trauma patients upon admission to the ER.

Coagulation time (CT) in ROTEM or reaction time ( $r$ time) in TEG serve as surrogate markers for the speed of initiation of coagulation and can be considered as the whole-blood PT or aPTT. Weiss et al. studied PTI, aPTT, EXTEM CT and INTEM CT in a dilution model [84]. A linear relationship was observed between either PTI or aPTT and the concentration of coagulation factors. However, EXTEM CT remained $<80$ seconds (normal range) until coagulation factor activity fell below $\sim 35 \%$ of normal.

Therefore, in the AUVA treatment algorithm, EXTEM $\mathrm{CT}>80$ seconds and INTEM CT $>240$ seconds indicate a need for treatment to improve thrombin generation (Figure 2). 
Current options for increasing thrombin generation during trauma-related bleeding include FFP, prothrombin complex concentrate (PCC) and activated recombinant factor VII (rFVIIa) [8,37,85-87]. rVIIa was studied in two randomized controlled trials and failed to show a survival benefit $[85,88]$.

Limited data on the use of PCC in trauma are currently available. In one study, administration of fibrinogen concentrate $(\mathrm{n}=128)$, along with PCC $(\mathrm{n}=98)$, in trauma patients $(n=131)$ produced more favourable survival rates than those predicted by the trauma injury severity score (TRISS) or revised injury severity classification (RISC) score [8]. Schöchl et al. also reported significantly higher transfusion rates for $\mathrm{RBC}$ and $\mathrm{PC}$ among trauma patients receiving haemostatic therapy with allogeneic blood products only, compared with those receiving coagulation factor concentrates [86]. However, no randomized controlled trials have been conducted to investigate this concept.

Robust safety data are lacking for the use of PCCs in the treatment of TIC. PCC is a procoagulant drug, and a possible risk of thromboembolic adverse events must be considered alongside patients' possible tendency towards thrombosis following trauma [79,89-91]. The risk of haemostatic imbalance relating to the prothrombotic nature of PCC therapy may be offset by the use of viscoelastic coagulation monitoring (EXTEM CT) to minimize the risk of excessive dosing. Although some PCCs contain the anticoagulant proteins $\mathrm{C}, \mathrm{S}$ and $\mathrm{Z}$, the main antagonist of factor II (antithrombin, ATIII) is either absent from PCC or present in far smaller quantities than would be needed to balance the procoagulant potential of factor II [92]. In addition, the administered quantity of factor II may be higher than that suggested by the labeled dose, because PCCs are standardized according to factor IX (e. g. in one product investigated by Kalina et al., the ratio of FII:FIX was 1.6) [92]. Co-administration of ATIII with PCC may be an option, particularly in patients with a lack of coagulation inhibitors. When time is available (e. g. oozing bleeding, in either the operating room or the ICU), the plasma ATIII level should be measured before PCC administration. However, clinical trial data are needed to confirm best practice regarding potential ATIII co-administration.

AUVA TRAUMA HOSPITAL TREATMENT ALGORITHM FOR TIC

Prolongation of EXTEM CT $>80$ seconds

1. Rule out the following reasons for $\mathrm{CT}$ prolongation:

fibrinolysis (APTEM CT < EXTEM CT [not well established for assessing fibrinolysis])

heparin effect (HEPTEM CT < INTEM CT [e.g. following transfusion of cell- saver blood].
2. EXTEM CT $>80$ seconds serves as a surrogate parameter for insufficient thrombin generation. PCC is a treatment option for improving thrombin production.

\section{Improvement of clot stability}

Hyperfibrinolysis is associated with high mortality and increased risk of MT [13-15]. Kashuk et al. reported that even a small reduction (1 unit) in TEG clot strength ( $G$ value) 1 hour post-injury increased mortality by $>10 \%$, and that primary fibrinolysis occurs in a higher percentage of patients requiring $\mathrm{MT}$ than in the overall group of trauma patients (34\% vs. $18 \%$ ) [13].

These observations are in line with data from the CRASH-2 study which showed an improved survival rate in patients receiving early antifibrinolytic therapy (tranexamic acid [TXA] $1 \mathrm{~g}$ over 10 minutes followed by an infusion of $1 \mathrm{~g}$ over 8 hours). Mortality in the placebo group was $16 \%$, whereas in the TXA group it was $14.5 \%$ [87]. Surprisingly, mortality was increased among patients receiving TXA later than 3 hours post-trauma [93].

\section{AUVA TRAUMA HOSPITAL TREATMENT ALGORITHM FOR TIC}

TXA (15-20 mg per kg bodyweight) should be administered to all major trauma patients (ISS > 16), to all trauma patients admitted in shock, and to all trauma patients with hyperfibrinolysis confirmed by ROTEM test results (any major improvement in APTEM parameters compared to corresponding EXTEM parameters).

Figure 2 depicts the "theragnostic" algorithm established in the AUVA Trauma Hospital, Salzburg, and Figure 3 displays an example of a severe bleeding patient treated according to this algorithm. The algorithm is not currently supported by data from randomized controlled trials, but clinical evidence has indicated its viability in terms of safety and effectiveness $[8,86]$. Because of the poor evidence base and international variations in the approval status of coagulation factor concentrates, it would be inappropriate to advocate widespread adoption at this stage. However, the lack of well-designed randomized controlled trials supporting the use of allogeneic blood products must also be considered [94], together with the empirical advantages of individualized, goaldirected therapy.

\section{Conclusion}

The "theragnostic" concept is based on rapidly available whole-blood viscoelastic test results. Haemostatic therapy is individualized according to the patient's actual needs. Compared with predefined ratio-driven 

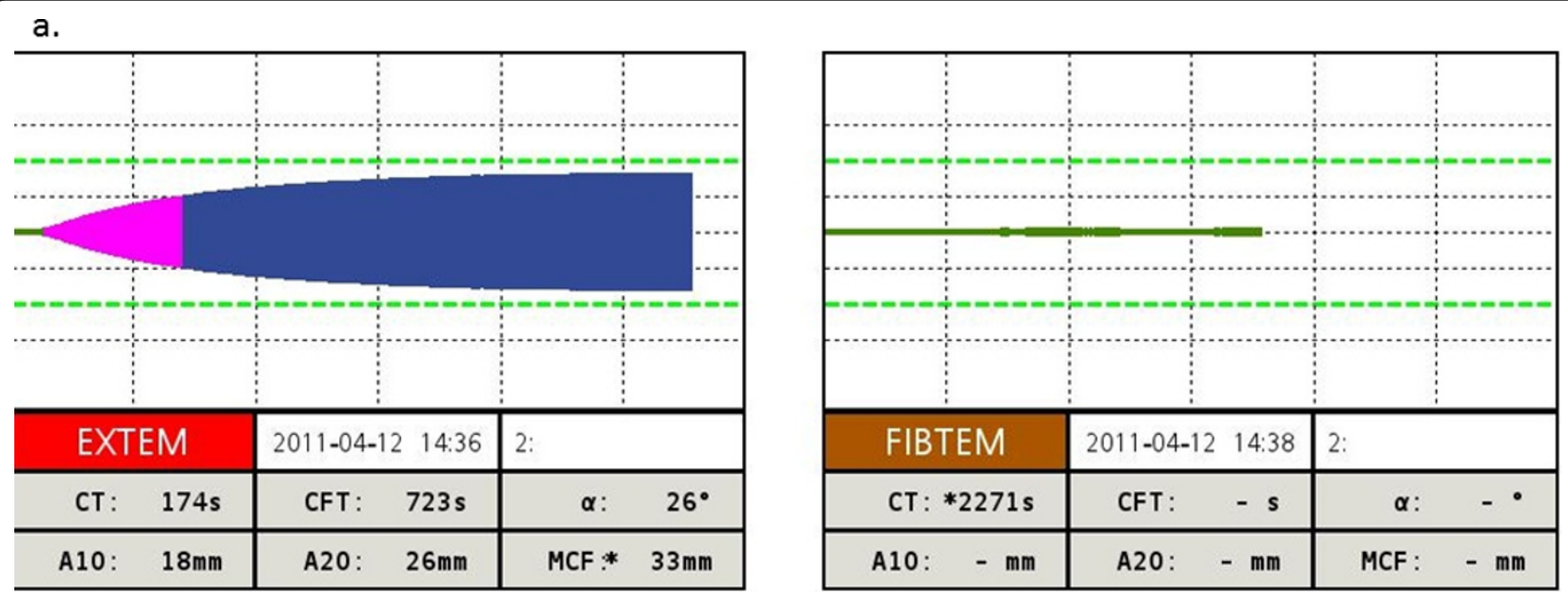

b.
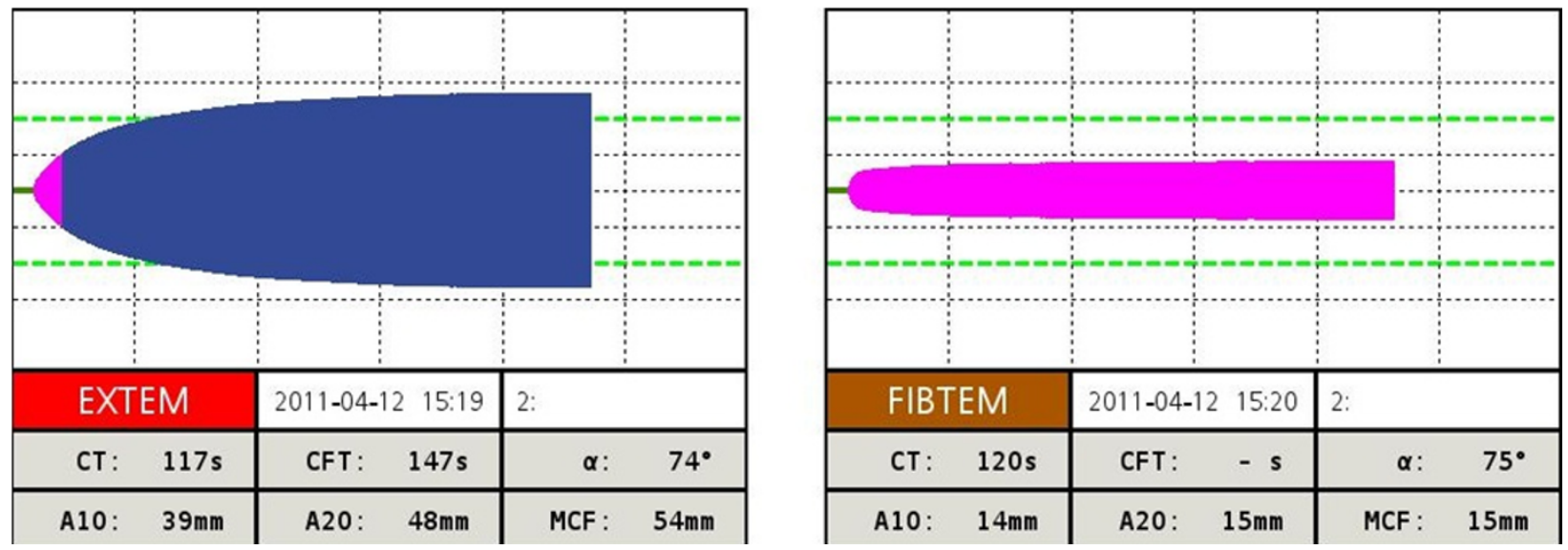

Figure 3 ROTEM traces from a trauma patient treated according to the AUVA Trauma Hospital algorithm: a. upon admission to the ER (EXTEM coagulation time and clot formation time are prolonged; maximum clot firmness is reduced; no clot formation in the FIBTEM test). b. 40 minutes after treatment with $2 \mathrm{~g}$ tranexamic acid, $10 \mathrm{~g}$ fibrinogen concentrate, $1800 \mathrm{U}$ prothrombin complex concentrate and $1250 \mathrm{U}$ factor XIII (normal coagulation).

approaches to administering allogeneic blood products, individualized coagulation management potentially reduces the risks of both under-transfusion (increased risk of bleeding) and over-transfusion (increased risk of ARDS, acute lung injury, sepsis and MOF). Coagulation factor concentrates offer possible advantages over FFP, but the potential risks must be considered carefully. To confirm the efficacy and safety of individualized haemostatic management based on coagulation viscoelastic tests, randomized controlled studies are mandatory.

\section{Abbreviations}

aPTT: activated partial thromboplastin time; ALl: acute lung injury; ARDS: acute respiratory distress syndrome; CA10: clot amplitude after 10 minutes' running time; CT: coagulation time; CFT: clot formation time; CP: cryoprecipitate; ER: emergency room; FFP: fresh-frozen plasma; HF: hyperfibrinolysis; ICU: intensive care unit; k-time: kinetic time; MA: maximum amplitude; MCF: maximum clot firmness; MOF: multiple organ failure; INR: international normalized ratio; MT: massive transfusion; MTP: massive transfusion protocol; PC: platelet concentrate; PCC: prothrombin complex concentrate; POC: point of care; PT: prothrombin time; PTI: prothrombin time index; RBC: red blood cells; r-time: reaction time; ROTEM: rotational thromboelastometry; TRALI: transfusion-related lung injury; TEG: thrombelastography; TIC: trauma-induced coagulopathy; TXA: tranexamic acid; U: units

\section{Author details}

'Ludwig Boltzmann Institute of Experimental and Clinical Traumatology, Vienna, Austria. ${ }^{2}$ Department of Anaesthesiology and Intensive Care Medicine, AUVA Trauma Centre, Salzburg, Austria. ${ }^{3}$ Department of Trauma and Orthopaedic Surgery, University of Witten/Herdecke, Cologne-Merheim Medical Centre (CMMC), Cologne, Germany. ${ }^{4}$ Department of Anaesthesiology and Intensive Care Medicine, University Hospital of Essen, Essen, Germany.

\section{Authors' contributions}

HS wrote the initial draft of the manuscript and performed the literature research. WV, MM, CS and KG edited and reworded parts of the manuscript. All authors read and approved the final manuscript.

\section{Competing interests}

HS, CS, MM and KG received speakers' fee from CSL Behring and TEM international. HS and CS received research grants from CSL Behring. TEM international provided reagents and devices for studies. WV declares no competing interest. 
Received: 25 December 2011 Accepted: 24 February 2012

Published: 24 February 2012

\section{References}

1. Kauvar DS, Wade CE: The epidemiology and modern management of traumatic hemorrhage: US and international perspectives. Crit Care 2005, 9(Suppl 5):S1-9.

2. Sauaia A, Moore FA, Moore EE, Moser KS, Brennan R, Read RA, Pons PT: Epidemiology of trauma deaths: a reassessment. J Trauma 1995, 38(2):185-193.

3. Tien HC, Spencer F, Tremblay LN, Rizoli SB, Brenneman FD: Preventable deaths from hemorrhage at a level I Canadian trauma center. J Trauma 2007, 62(1):142-146.

4. Brohi K, Singh J, Heron M, Coats T: Acute traumatic coagulopathy. J Trauma 2003, 54(6):1127-1130.

5. Maegele M, Lefering R, Yucel N, Tjardes T, Rixen D, Paffrath T, Simanski C, Neugebauer E, Bouillon B: Early coagulopathy in multiple injury: an analysis from the German Trauma Registry on 8724 patients. Injury 2007, 38(3):298-304

6. Johansson PI: Goal-directed hemostatic resuscitation for massively bleeding patients: the Copenhagen concept. Transfus Apher Sci 2010, 43(3):401-405.

7. Kashuk JL, Moore EE, Johnson JL, Haenel J, Wilson M, Moore JB, Cothren CC, Biffl WL, Banerjee A, Sauaia A: Postinjury life threatening coagulopathy: is 1:1 fresh frozen plasma:packed red blood cells the answer? J Trauma 2008, 65(2):261-270.

8. Schochl H, Nienaber U, Hofer G, Voelckel W, Jambor C, Scharbert G, Kozek Langenecker S, Solomon C: Goal-directed coagulation management of major trauma patients using thromboelastometry (ROTEM)-guided administration of fibrinogen concentrate and prothrombin complex concentrate. Crit Care 2010, 14(2):R55.

9. Chambers LA, Chow SJ, Shaffer LE: Frequency and characteristics of coagulopathy in trauma patients treated with a low- or high-plasmacontent massive transfusion protocol. Am J Clin Pathol 2011, 136(3):364-370.

10. Hoffman M, Monroe DM: A cell-based model of hemostasis. Thromb Haemost 2001, 85(6):958-965.

11. Falati $\mathrm{S}$, Gross $P$, Merrill-Skoloff G, Furie BC, Furie B: Real-time in vivo imaging of platelets, tissue factor and fibrin during arterial thrombus formation in the mouse. Nat Med 2002, 8(10):1175-1181.

12. Mann KG, Brummel K, Butenas S: What is all that thrombin for? J Thromb Haemost 2003, 1(7):1504-1514.

13. Kashuk JL, Moore EE, Sawyer M, Wohlauer M, Pezold M, Barnett C, Biffl WL, Burlew CC, Johnson JL, Sauaia A: Primary fibrinolysis is integral in the pathogenesis of the acute coagulopathy of trauma. Ann Surg 2010, 252(3):434-442.

14. Schochl H, Frietsch T, Pavelka M, Jambor C: Hyperfibrinolysis after major trauma: differential diagnosis of lysis patterns and prognostic value of thrombelastometry. J Trauma 2009, 67(1):125-131.

15. Theusinger OM, Wanner GA, Emmert MY, Billeter A, Eismon J, Seifert B, Simmen HP, Spahn DR, Baulig W: Hyperfibrinolysis diagnosed by rotational thromboelastometry (ROTEM) is associated with higher mortality in patients with severe trauma. Anesth Analg 2011, 113(5):1003-1012.

16. Ganter MT, Hofer CK: Coagulation monitoring: current techniques and clinical use of viscoelastic point-of-care coagulation devices. Anesth Analg 2008, 106(5):1366-1375.

17. Dunbar NM, Chandler WL: Thrombin generation in trauma patients. Transfusion 2009, 49(12):2652-2660.

18. Hiippala ST, Myllyla GJ, Vahtera EM: Hemostatic factors and replacement of major blood loss with plasma-poor red cell concentrates. Anesth Analg 1995, 81(2):360-365.

19. Fries $D$, Martini WZ: Role of fibrinogen in trauma-induced coagulopathy. Br J Anaesth 2010, 105(2):116-121.

20. Adam S, Karger R, Kretschmer V: Photo-optical methods can lead to clinically relevant overestimation of fibrinogen concentration in plasma diluted with hydroxyethyl starch. Clin Appl Thromb Hemost 2010 16(4):461-471

21. Fenger-Eriksen C, Moore GW, Rangarajan S, Ingerslev J, Sorensen B: Fibrinogen estimates are influenced by methods of measurement and hemodilution with colloid plasma expanders. Transfusion 2010, 50(12):2571-2576.

22. Fenger-Eriksen C, Tonnesen E, Ingerslev J, Sorensen B: Mechanisms of hydroxyethyl starch-induced dilutional coagulopathy. J Thromb Haemost 2009, 7(7):1099-1105.

23. Davenport R, Manson J, De'ath H, Platton S, Coates A, Allard S, Hart D, Pearse R, Pasi K, Maccallum P, Stanworth S, Brohi K: Functional definition and characterization of acute traumatic coagulopathy. Crit Care Med 2011, 39(12):2652-2658.

24. Toulon P, Ozier Y, Ankri A, Fleron MH, Leroux G, Samama CM: Point-of-care versus central laboratory coagulation testing during haemorrhagic surgery. A multicenter study. Thromb Haemost 2009, 101(2):394-401.

25. Wilson RF, Dulchavsky SA, Soullier G, Beckman B: Problems with 20 or more blood transfusions in 24 hours. Am Surg 1987, 53(7):410-417.

26. Cotton BA, Faz G, Hatch QM, Radwan ZA, Podbielski J, Wade C, Kozar RA, Holcomb JB: Rapid thrombelastography delivers real-time results that predict transfusion within 1 hour of admission. J Trauma 2011, 71(2):407-414

27. Johansson PI, Stissing T, Bochsen L, Ostrowski SR: Thrombelastography and thromboelastometry in assessing coagulopathy in trauma. Scand J Trauma Resusc Emerg Med 2009, 17:45.

28. Kashuk JL, Moore EE, Sawyer M, Le T, Johnson J, Biffl WL, Cothren CC, Barnett C, Stahel P, Sillman CC, Sauaia A, Banerjee A: Postinjury coagulopathy management: goal directed resuscitation via $\mathrm{POC}$ thrombelastography. Ann Surg 2010, 251(4):604-614

29. Rossaint R, Bouillon B, Cerny V, Coats TJ, Duranteau J, FernandezMondejar E, Hunt BJ, Komadina R, Nardi G, Neugebauer E, Ozier Y, Riddez L, Schultz A, Stahel PF, Vincent JL, Spahn DR: Management of bleeding following major trauma: an updated European guideline. Crit Care 2010, 14(2):R52.

30. Schochl H, Cotton B, Inaba K, Nienaber U, Fischer H, Voelckel W, Solomon C: FIBTEM provides early prediction of massive transfusion in trauma. Crit Care 2011, 15(6):R265.

31. Luddington RJ: Thrombelastography/thromboelastometry. Clin Lab Haematol 2005, 27(2):81-90.

32. Solomon C, Traintinger S, Ziegler B, Hanke A, Rahe-Meyer N, Voelckel W, Schochl H: Platelet function following trauma. A Multiple Electrode Aggregometry study. Thromb Haemost 2011, 106(2):322-330.

33. Swallow RA, Agarwala RA, Dawkins KD, Curzen NP: Thromboelastography: potential bedside tool to assess the effects of antiplatelet therapy? Platelets 2006, 17(6):385-392.

34. Toth O, Calatzis A, Penz S, Losonczy H, Siess W: Multiple electrode aggregometry: a new device to measure platelet aggregation in whole blood. Thromb Haemost 2006, 96(6):781-788

35. Geeraedts LM, Demiral H, Schaap NP, Kamphuisen PW, Pompe JC, Frolke JP. 'Blind' transfusion of blood products in exsanguinating trauma patients. Resuscitation 2007, 73(3):382-388.

36. Gonzalez EA, Moore FA, Holcomb JB, Miller CC, Kozar RA, Todd SR, Cocanour CS, Balldin BC, McKinley BA: Fresh frozen plasma should be given earlier to patients requiring massive transfusion. J Trauma 2007, 62(1):112-119.

37. Borgman MA, Spinella PC, Perkins JG, Grathwohl KW, Repine T, Beekley AC, Sebesta J, Jenkins D, Wade CE, Holcomb JB: The ratio of blood products transfused affects mortality in patients receiving massive transfusions at a combat support hospital. J Trauma 2007, 63(4):805-813.

38. Cotton BA, Au BK, Nunez TC, Gunter OL, Robertson AM, Young PP: Predefined massive transfusion protocols are associated with a reduction in organ failure and postinjury complications. J Trauma 2009, 66(1):41-48

39. Duchesne JC, Kimonis K, Marr AB, Rennie KV, Wahl G, Wells JE, Islam TM, Meade P, Stuke L, Barbeau JM, Hunt JP, Baker CC, McSwain NE Jr: Damage control resuscitation in combination with damage control laparotomy: a survival advantage. J Trauma 2010, 69(1):46-52.

40. Holcomb JB, Wade CE, Michalek JE, Chisholm GB, Zarzabal LA, Schreiber MA, Gonzalez EA, Pomper GJ, Perkins JG, Spinella PC, Williams KL, Park MS: Increased plasma and platelet to red blood cell ratios improves outcome in $\mathbf{4 6 6}$ massively transfused civilian trauma patients. Ann Surg 2008, 248(3):447-458

41. Lustenberger T, Frischknecht A, Bruesch M, Keel MJ: Blood component ratios in massively transfused, blunt trauma patients-a time-dependent covariate analysis. J Trauma 2011, 71(5):1144-1150. 
42. Maegele M, Lefering R, Paffrath T, Tjardes T, Simanski C, Bouillon B: Redblood-cell to plasma ratios transfused during massive transfusion are associated with mortality in severe multiple injury: a retrospective analysis from the Trauma Registry of the Deutsche Gesellschaft fur Unfallchirurgie. Vox Sang 2008, 95(2):112-119.

43. Cotton BA, Gunter OL, Isbell J, Au BK, Robertson AM, Morris JA, St Jacques P, Young PP: Damage control hematology: the impact of a trauma exsanguination protocol on survival and blood product utilization. J Trauma 2008, 64(5):1177-1182.

44. Johansson PI, Stensballe J: Effect of Haemostatic Control Resuscitation on mortality in massively bleeding patients: a before and after study. Vox Sang 2009, 96(2):111-118.

45. Schuster KM, Davis KA, Lui FY, Maerz LL, Kaplan L: The status of massive transfusion protocols in United States trauma centers: massive transfusion or massive confusion? Transfusion 2010, 50(7):1545-1551.

46. Cotton BA, Dossett LA, Haut ER, Shafi S, Nunez TC, Au BK, Zaydfudim V, Johnston M, Arbogast P, Young PP: Multicenter validation of a simplified score to predict massive transfusion in trauma. J Trauma 2010, 69(Suppl 1):S33-39.

47. McLaughlin DF, Niles SE, Salinas J, Perkins JG, Cox ED, Wade CE, Holcomb JB: A predictive model for massive transfusion in combat casualty patients. J Trauma 2008, 64(2 Suppl):S57-63.

48. Rainer TH, Ho AM, Yeung JH, Cheung NK, Wong RS, Tang N, Ng SK, Wong GK, Lai PB, Graham CA: Early risk stratification of patients with major trauma requiring massive blood transfusion. Resuscitation 2011, 82(6):724-729.

49. Yucel $N$, Lefering $R$, Maegele M, Vorweg M, Tjardes T, Ruchholtz S, Neugebauer EA, Wappler F, Bouillon B, Rixen D: Trauma Associated Severe Hemorrhage (TASH)-Score: probability of mass transfusion as surrogate for life threatening hemorrhage after multiple trauma. J Trauma 2006, 60(6):1228-1236.

50. Hirshberg A, Dugas M, Banez El, Scott BG, Wall MJ, Mattox KL: Minimizing dilutional coagulopathy in exsanguinating hemorrhage: a computer simulation. J Trauma 2003, 54(3):454-463.

51. Murad MH, Stubbs JR, Gandhi MJ, Wang AT, Paul A, Erwin PJ, Montori VM, Roback JD: The effect of plasma transfusion on morbidity and mortality: a systematic review and meta-analysis. Transfusion 2010, 50(6):1370-1383.

52. Davenport R, Curry N, Manson J, De'Ath H, Coates A, Rourke C, Pearse R, Stanworth S, Brohi K: Hemostatic effects of fresh frozen plasma may be maximal at red cell ratios of 1:2. J Trauma 2011, 70(1):90-95.

53. Rahbar MH, Fox EE, Del Junco DJ, Cotton BA, Podbielski JM, Matijevic N, Cohen MJ, Schreiber MA, Zhang J, Mirhaji P, Duran SJ, Reynolds RJ, Benjamin-Garner R, Holcomb JB: Coordination and management of multicenter clinical studies in trauma: Experience from the PRospective Observational Multicenter Major Trauma Transfusion (PROMMTT) Study. Resuscitation 2011.

54. Simmons JW, White CE, Eastridge BJ, Mace JE, Wade CE, Blackbourne LH: Impact of policy change on US Army combat transfusion practices. $J$ Trauma 2010, 69(Suppl 1):S75-80.

55. Dirks J, Jorgensen $H$, Jensen $\mathrm{CH}$, Ostrowski SR, Johansson PI: Blood product ratio in acute traumatic coagulopathy-effect on mortality in a Scandinavian level 1 trauma centre. Scand J Trauma Resusc Emerg Med 2010, 18:65.

56. Riskin DJ, Tsai TC, Riskin L, Hernandez-Boussard T, Purtill M, Maggio PM, Spain DA, Brundage SI: Massive transfusion protocols: the role of aggressive resuscitation versus product ratio in mortality reduction. J Am Coll Surg 2009, 209(2):198-205.

57. de Biasi AR, Stansbury LG, Dutton RP, Stein DM, Scalea TM, Hess JR: Blood product use in trauma resuscitation: plasma deficit versus plasma ratio as predictors of mortality in trauma (CME). Transfusion 2011, 51(9):1925-1932

58. Chaiwat O, Lang JD, Vavilala MS, Wang J, MacKenzie EJ, Jurkovich GJ, Rivara FP: Early packed red blood cell transfusion and acute respiratory distress syndrome after trauma. Anesthesiology 2009, 110(2):351-360.

59. Inaba K, Branco BC, Rhee P, Blackbourne LH, Holcomb JB, Teixeira PG, Shulman I, Nelson J, Demetriades D: Impact of plasma transfusion in trauma patients who do not require massive transfusion. J Am Coll Surg 2010, 210(6):957-965

60. Johnson JL, Moore EE, Kashuk JL, Banerjee A, Cothren CC, Biffl WL, Sauaia A Effect of blood products transfusion on the development of postinjury multiple organ failure. Arch Surg 2010, 145(10):973-977.
61. Sambasivan CN, Kunio NR, Nair PV, Zink KA, Michalek JE, Holcomb JB, Schreiber MA, Wade CE, Brasel KJ, Vercruysse G, MacLeod J, Dutton RP, Hess JR, Duchesne JC, McSwain NE, Muskat P, Johannigamn J, Cryer HM, Tillou A, Cohen MJ, Pittet JF, Knudson P, De Moya MA, Tieu B, Brundage S, Napolitano LM, Brunsvold M, Sihler KC, Beilman G, Peitzman AB, et al: High ratios of plasma and platelets to packed red blood cells do not affect mortality in nonmassively transfused patients. J Trauma 2011, 71(2 Suppl 3):S329-336.

62. Watson GA, Sperry JL, Rosengart MR, Minei JP, Harbrecht BG, Moore EE, Cuschieri J, Maier RV, Billiar TR, Peitzman AB: Fresh frozen plasma is independently associated with a higher risk of multiple organ failure and acute respiratory distress syndrome. J Trauma 2009, 67(2):221-227.

63. Leemann H, Lustenberger T, Talving P, Kobayashi L, Bukur M, Brenni M, Bruesch M, Spahn DR, Keel MJ: The role of rotation thromboelastometry in early prediction of massive transfusion. J Trauma 2010, 69(6):1403-1408

64. Nystrup KB, Windelov NA, Thomsen AB, Johansson Pl: Reduced clot strength upon admission, evaluated by thrombelastography (TEG), in trauma patients is independently associated with increased 30-day mortality. Scand J Trauma Resusc Emerg Med 2011, 19:52.

65. Pezold M, Moore EE, Wohlauer M, Sauaia A, Gonzalez E, Banerjee A, Silliman CC: Viscoelastic clot strength predicts coagulation-related mortality within 15 minutes. Surgery 2011.

66. Plotkin AJ, Wade CE, Jenkins DH, Smith KA, Noe JC, Park MS, Perkins JG, Holcomb JB: A reduction in clot formation rate and strength assessed by thrombelastography is indicative of transfusion requirements in patients with penetrating injuries. J Trauma 2008, 64(2 Suppl):S64-68.

67. Schochl H, Solomon C, Traintinger S, Nienaber U, Tacacs-Tolnai A, Windhofer C, Bahrami S, Voelckel W: Thromboelastometric (ROTEM) Findings in Patients Suffering from Isolated Severe Traumatic Brain Injury. J Neurotrauma 2011, 28(10):2033-2041.

68. Stinger HK, Spinella PC, Perkins JG, Grathwohl KW, Salinas J, Martini WZ, Hess JR, Dubick MA, Simon CD, Beekley AC, Wolf SE, Wade CE, Holcomb JB: The ratio of fibrinogen to red cells transfused affects survival in casualties receiving massive transfusions at an army combat support hospital. J Trauma 2008, 64(2 Suppl):S79-85

69. Theusinger OM, Baulig W, Seifert B, Emmert MY, Spahn DR, Asmis LM: Relative concentrations of haemostatic factors and cytokines in solvent/ detergent-treated and fresh-frozen plasma. Br J Anaesth 2011, 106(4):505-511.

70. Chowdhury P, Saayman AG, Paulus U, Findlay GP, Collins PW: Efficacy of standard dose and $30 \mathrm{ml} / \mathrm{kg}$ fresh frozen plasma in correcting laboratory parameters of haemostasis in critically ill patients. $\mathrm{Br} J$ Haematol 2004, 125(1):69-73.

71. Shuja F, Shults C, Duggan M, Tabbara M, Butt MU, Fischer TH, Schreiber MA, Tieu B, Holcomb JB, Sondeen JL, Demoya M, Velmahos GC, Alam HB: Development and testing of freeze-dried plasma for the treatment of trauma-associated coagulopathy. J Trauma 2008, 65(5):975-985.

72. Sorensen B, Bevan D: A critical evaluation of cryoprecipitate for replacement of fibrinogen. Br J Haematol 2010, 149(6):834-843.

73. Callum JL, Karkouti K, Lin Y: Cryoprecipitate: the current state of knowledge. Transfus Med Rev 2009, 23(3):177-188.

74. Nascimento B, Rizoli S, Rubenfeld G, Fukushima R, Ahmed N, Nathens A, Lin Y, Callum J: Cryoprecipitate transfusion: assessing appropriateness and dosing in trauma. Transfus Med 2011, 21(6):394-401.

75. Rahe-Meyer N, Sorensen B: For: Fibrinogen concentrate for management of bleeding. J Thromb Haemost 2011, 9(1):1-5.

76. Solomon C, Pichlmaier U, Schoechl H, Hagl C, Raymondos K, Scheinichen D, Koppert W, Rahe-Meyer N: Recovery of fibrinogen after administration of fibrinogen concentrate to patients with severe bleeding after cardiopulmonary bypass surgery. Br J Anaesth 2010, 104(5):555-562.

77. Dickneite G, Pragst I, Joch C, Bergman GE: Animal model and clinical evidence indicating low thrombogenic potential of fibrinogen concentrate (Haemocomplettan P). Blood Coagul Fibrinolysis 2009, 20(7):535-540.

78. Kozek-Langenecker S, Sorensen B, Hess JR, Spahn DR: Clinical effectiveness of fresh frozen plasma compared with fibrinogen concentrate: $a$ systematic review. Crit Care 2011, 15(5):R239.

79. Sorensen B, Spahn DR, Innerhofer P, Spannagl M, Rossaint R: Clinical review: Prothrombin complex concentrates-evaluation of safety and thrombogenicity. Crit Care 2011, 15(1):201. 
80. Hess JR, Lindell AL, Stansbury LG, Dutton RP, Scalea TM: The prevalence of abnormal results of conventional coagulation tests on admission to a trauma center. Transfusion 2009, 49(1):34-39.

81. Allen SR, Kashuk JL: Unanswered questions in the use of blood component therapy in trauma. Scand J Trauma Resusc Emerg Med 2011, 19:5.

82. Tauber H, Innerhofer P, Breitkopf R, Westermann I, Beer R, El Attal R, Strasak A, Mittermayr M: Prevalence and impact of abnormal ROTEM(R) assays in severe blunt trauma: results of the 'Diagnosis and Treatment of Trauma-Induced Coagulopathy (DIA-TRE-TIC) study'. Br J Anaesth 2011, 107(3):378-387.

83. Brohi K, Cohen MJ, Ganter MT, Schultz MJ, Levi M, Mackersie RC, Pittet JF: Acute coagulopathy of trauma: hypoperfusion induces systemic anticoagulation and hyperfibrinolysis. J Trauma 2008, 64(5):1211-1217.

84. Weiss G, Lison S, Spannagl M, Heindl B: Expressiveness of global coagulation parameters in dilutional coagulopathy. Br J Anaesth 2010, 105(4):429-436.

85. Boffard KD, Riou B, Warren B, Choong PI, Rizoli S, Rossaint R, Axelsen M, Kluger $Y$ : Recombinant factor Vlla as adjunctive therapy for bleeding control in severely injured trauma patients: two parallel randomized, placebo-controlled, double-blind clinical trials. J Trauma 2005, 59(1):8-15.

86. Schochl H, Nienaber U, Maegele M, Hochleitner G, Primavesi F, Steitz B, Arndt C, Hanke A, Voelckel W, Solomon C: Transfusion in trauma: thromboelastometry-guided coagulation factor concentrate-based therapy versus standard fresh frozen plasma-based therapy. Crit Care 2011, 15(2):R83.

87. Shakur H, Roberts I, Bautista R, Caballero J, Coats T, Dewan Y, El-Sayed H, Gogichaishvili T, Gupta S, Herrera J, Hunt B, Iribhogbe P, Izurieta M, Khamis H, Komolafe E, Marrero MA, Mejia-Mantilla J, Miranda J, Morales C, Olaomi O, Olldashi F, Perel P, Peto R, Ramana PV, Ravi RR, Yutthakasemsunt S: Effects of tranexamic acid on death, vascular occlusive events, and blood transfusion in trauma patients with significant haemorrhage (CRASH-2): a randomised, placebo-controlled trial. Lancet 2010, 376(9734):23-32.

88. Hauser CJ, Boffard K, Dutton R, Bernard GR, Croce MA, Holcomb JB, Leppaniemi A, Parr M, Vincent JL, Tortella BJ, Dimsits J, Bouillon B: Results of the CONTROL trial: efficacy and safety of recombinant activated Factor VII in the management of refractory traumatic hemorrhage. $J$ Trauma 2010, 69(3):489-500.

89. Grottke O, Braunschweig T, Spronk HM, Esch S, Rieg AD, van Oerle R, ten Cate H, Fitzner C, Tolba R, Rossaint R: Increasing concentrations of prothrombin complex concentrate induce disseminated intravascular coagulation in a pig model of coagulopathy with blunt liver injury. Blood 2011, 118(7):1943-1951

90. Warren O, Simon B: Massive, fatal, intracardiac thrombosis associated with prothrombin complex concentrate. Ann Emerg Med 2009, 53(6):758-761.

91. Toker S, Hak DJ, Morgan SJ: Deep vein thrombosis prophylaxis in trauma patients. Thrombosis 2011, 2011:505373.

92. Kalina U, Bickhard H, Schulte S: Biochemical comparison of seven commercially available prothrombin complex concentrates. Int $\mathrm{C}$ Clin Pract 2008, 62(10):1614-1622.

93. Roberts I, Shakur H, Afolabi A, Brohi K, Coats T, Dewan Y, Gando S, Guyatt G, Hunt BJ, Morales C, Perel P, Prieto-Merino D, Woolley T: The importance of early treatment with tranexamic acid in bleeding trauma patients: an exploratory analysis of the $\mathrm{CRASH}-2$ randomised controlled trial. Lancet 2011, 377(9771):1096-1101.

94. Yang L, Stanworth S, Hopewell S, Doree C, Murphy M: Is fresh-frozen plasma clinically effective? An update of a systematic review of randomized controlled trials. Transfusion 2012.

doi:10.1186/1757-7241-20-15

Cite this article as: Schöchl et al: Early and individualized goal-directed therapy for trauma-induced coagulopathy. Scandinavian Journal of Trauma, Resuscitation and Emergency Medicine 2012 20:15.

\section{Submit your next manuscript to BioMed Central and take full advantage of:}

- Convenient online submission

- Thorough peer review

- No space constraints or color figure charges

- Immediate publication on acceptance

- Inclusion in PubMed, CAS, Scopus and Google Scholar

- Research which is freely available for redistribution

Submit your manuscript at www.biomedcentral.com/submit 